\title{
Analysis of flame stabilization limit in a cylindrical of step micro- combustor with different material through the numerical simulation
}

\author{
Herman Saputro ${ }^{1, *}$, Aris Purwanto $^{1}$, Laila Fitriana $^{2}$, Danar $S$ Wijayanto ${ }^{1}$, Valiant L $P$ Sutrisno ${ }^{1}$, Eka D Ariyanto ${ }^{1}$, Marshal \\ Bima $^{1}$, Yuda Pratama $^{1}$, Heri Juwantono ${ }^{1}$, Tutuko Firdani ${ }^{1}$, Riyadi Muslim ${ }^{1}$, Fudhail A Munir ${ }^{3}$ \\ ${ }^{1}$ Department of Mechanical Engineering Education, Universitas Sebelas Maret, J1. Ahmad Yani No.200, Pabelan, Surakarta, Indonesia \\ ${ }^{2}$ Department of Mathematic Education, Universitas Sebelas Maret, J1. Ir. Sutami 36A, Surakarta, Indonesia \\ ${ }^{3}$ Faculty of Mechanical Engineering, Universiti Teknikal Malaysia Melaka, 76100 Hang Tuah Jaya, Durian Tunggal Melaka Malaysia
}

\begin{abstract}
The flame stabilization limit on micro-combustor had studied to support the micro power generator system. Micro-combustion became the crucial components in a micro power generation system as heat resource that will be converted into electricity. However, the unstable flame in micro-combustor became the main problem that faced by researchers, especially the excess of heat losses. The objective of this study is to observe the flame stabilization limit in a rearward facing step micro-combustor. This study was focused on the effect of micro-combustor material and flame stabilization through the numerical simulation. The micro-combustor material that was used in this study is quartz glass and stainless steel. Micro-combustor was divided into unburned region and burned region. The dimensions of micro-combustor are $3.5 \mathrm{~mm}$ inner diameter of unburned region, $4.5 \mathrm{~mm}$ inner diameter of burned region and $1 \mathrm{~mm}$ thickness. The results have shown that the material of micro-combustor and model of the flame holder have direct relationship with the characteristics of flame stabilization in the micro-combustors. The effects of the flame holder designs and micro-combustors dimensions on the flame stabilization were discussed in detail in this paper.
\end{abstract}

\section{Introduction}

In recent years, the innovation of electronic devices has been steadily increasing and leading to a small, portable and lightweight form. The improvement of this innovation needs to be accompanied by the provision of reliable power supply devices (batteries). The intended power supply is one that has high-specific energy, lightweight, small size and long duration [1]. Thus, the development of electronic equipment has led to innovation and research on power generation such as lithium-ion batteries and micro/meso power generators [2], [3], [4] and [5]. The micro power generation system has become a potential energy source because of its ability in energy storage per unit mass and power generation per unit volume.

Micro power generation system is a small-scale power generation by utilizing heat energy generated from a mechanism. The recent hydrocarbon-based micro-power generation system is one potential solution that provides better energy requirements for small devices compared to conventional lithium-ion batteries [4], [1] and [3] as shown in Fig. 1. The development of hydrocarbon-fueled hydrocarbon-based power generating devices has attracted much attention because hydrocarbons have much higher energy density than traditional batteries.

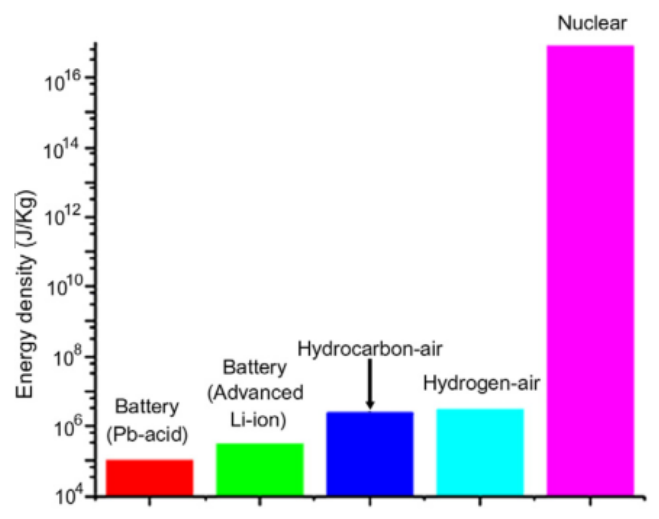

Fig. 1. Energy density of different energy systems [3].

However, the development of small-scale power generation using hydrocarbons facing obstacles on the difficulty to maintain a stable flame during the combustion process. The idea to stabilize the flame in micro combustor by installing wire mesh as a flame holder in micro combustors made of quartz glass was first proposed by Mikami et al.2013 [6]. Mikami et al. 2013 , reported that the flame could be stabilized in the combustor tube with an inner diameter below than the classical cooling distance. Khandelwal et al. [7] have conducted research using triple cylindrical rearward

\footnotetext{
"Corresponding author: hermansaputro@staff.uns.ac.id
} 
facing step to obtain a stable flame on the microcombustor. From the experiment results of Khandelwal et al. showed that the rearward step plays a significant function in stabilizing the flame in the micro combustor.

This study has been carried out numerical studies to obtain a stable flame by combining the two methods, i.e., the installation of wire mesh as a flame holder at the micro-combustor (by Mikami et al.) and the rearward step (by Khandelwal et al.). The objective of this study is to observe the flame stabilization limit in a rearward facing step micro-combustor. This study was focused on the effect of micro-combustor material and flame stabilization through the numerical simulation. The micro-combustor material was made from quartz glass and stainless steel, while the wire mesh is made of stainless steel. This study has used a numerical approach with Computational Fluid Dynamics (CFD) to determine the variables that affect the stability of flame in the micro-combustor. This approach is widely used in engineering such as in the research of [8], [9] [10] and [11].

\section{Numerical simulation}

The 3-D numerical simulation has been conducted to investigate the effect of combustor material and combustor model (rearward step with wire mesh as a flame holder) on the flame stabilization limits of micro combustors with gaseous fuels (propane-air combustion). The numerical simulation was performed using a threedimensional (3-D) steady-state by applying academic Computational Fluid Dynamics (CFD) software, ANSYS Release 16.2. The combustor was divided into two parts, i.e., the unburned and burned region by stainless steel wire mesh. The unburned and burned region has a different diameter as rearward step combustor model. The total length of unburned region is $30 \mathrm{~mm}$ with the inner diameter $3.5 \mathrm{~mm}$ and thickness is $1 \mathrm{~mm}$. The total length of burned region is $10 \mathrm{~mm}$ with the inner diameter $4.5 \mathrm{~mm}$ and thickness is $1 \mathrm{~mm}$. The total length of combustor is $40 \mathrm{~mm}$ (Fig. 2). Wire mesh has a rectangular hole with a length of $0.28 \mathrm{~mm}$ and a width of $0.14 \mathrm{~mm}$ as shown in Fig. 3. The 3-D numerical simulation of combustor type of rearward step with wire mesh as a flame holder employed the wire mesh with the wall conductivity $(\mathrm{k})=20 \mathrm{~W} / \mathrm{m} / \mathrm{K}$ refers to Munir and Mikami, 2015 [10]. Figure3 show the detail of the Schematic of the numerical simulation of combustor type of rearward step with wire mesh as a flame holder. The properties of thermodynamic and data of gas transport was obtained from Ansys academic Release 16.2 .

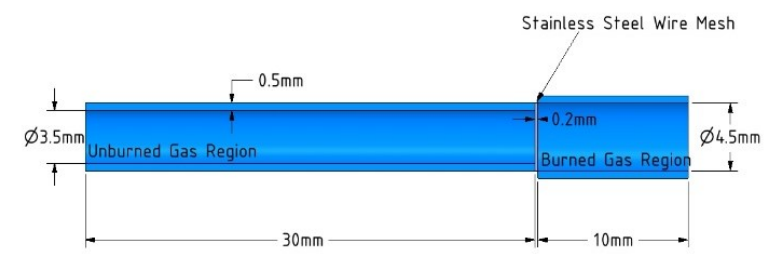

Fig. 2. Design of combustor type of rearward step with wire mesh as a flame holder.

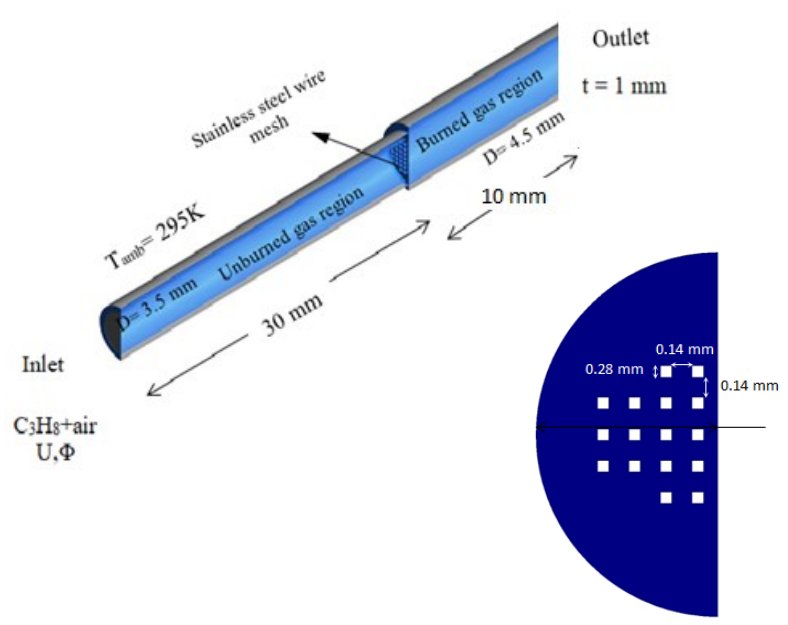

Fig. 3. Schematic of the numerical simulation of combustor type of rearward step with wire mesh as a flame holder.

\section{Result and discussion}

The simulation begins with cold flow technique assumption with flow velocity $0.20 \mathrm{~m} / \mathrm{s}$ where only the momentum and continuity equation is solved. The flow of fuel (propane + air) inside of the combustor was ignited at $1800 \mathrm{~K}$. The equivalent ratio between propane and air used in this simulation is $\varphi=1$. The focus of this numerical method is extinction limit, flame stabilization limit and blow off limit on some variations of flow velocity (U). The influence of combustor material (stainless steel and quartz glass) was studied in depth to know the performance of both materials as a material combustor.

Figure 5 shows the relationship between flow velocity $(U)$ and temperature $(T)$ of combustor type of rearward step with wire mesh using the stainless steel material and quartz glass material. The figure describes the extinction boundary limit, flame stabilization limit and blows off limit on some variation of flow velocity $(U)$. The stable flame area of the combustor type of rearward step with wire mesh and the equivalent ratio $\varphi=1$ occurs in flow velocity between $0.082-0.6 \mathrm{~m} / \mathrm{s}$ (for stainless steel material) and $0.1-0.6 \mathrm{~m} / \mathrm{s}$ (for quartz glass material). Meanwhile, the extinction limit area occurs in flow velocity $(U)$ less than $0.82 \mathrm{~m} / \mathrm{s}$ for stainless steel material and less than $0.1 \mathrm{~m} / \mathrm{s}$ for quartz glass material. The blow off limit area for stainless steel and quartz glass material occurs in the same flow velocity $(U)$ that is greater than $0.6 \mathrm{~m} / \mathrm{s}$. The maximum temperature generated by the stable flame on the combustor type of rearward step with wire mesh using stainless steel material is $2558.68 \mathrm{~K}$ underflow velocity (U) $0.25 \mathrm{~m} / \mathrm{s}$, whereas the maximum temperature in the combustor with quartz glass material is $2696.33 \mathrm{~K}$ underflow velocity $(U) 0.35 \mathrm{~m} / \mathrm{s}$. The following will discuss the conditions of flame in the area of extinction, flame stable and blow off. 


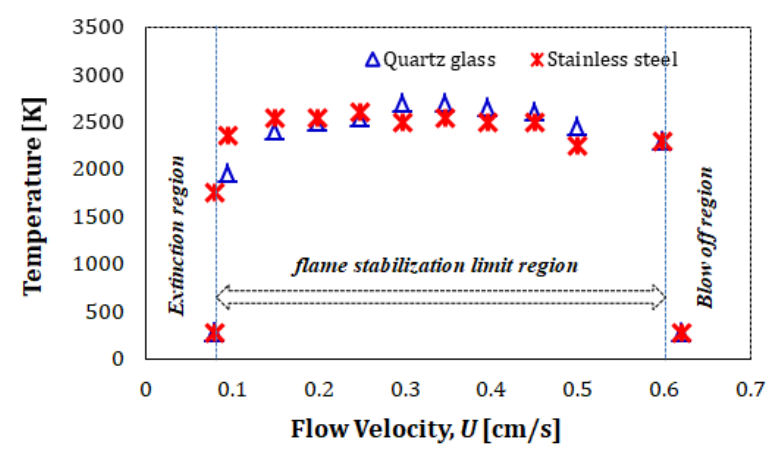

Fig. 5 The extinction boundary limit, flame stabilization limit and blows off limit combustor type of rearward step with wire mesh.

\subsection{Extinction area}

The combustor with stainless steel material has a lower extinction limit than quartz glass combustor. Stainless steel combustor extinguishes at $0.08 \mathrm{~m} / \mathrm{s}$, and quartz glass combustor extinguishes at $0.082 \mathrm{~m} / \mathrm{s}$.

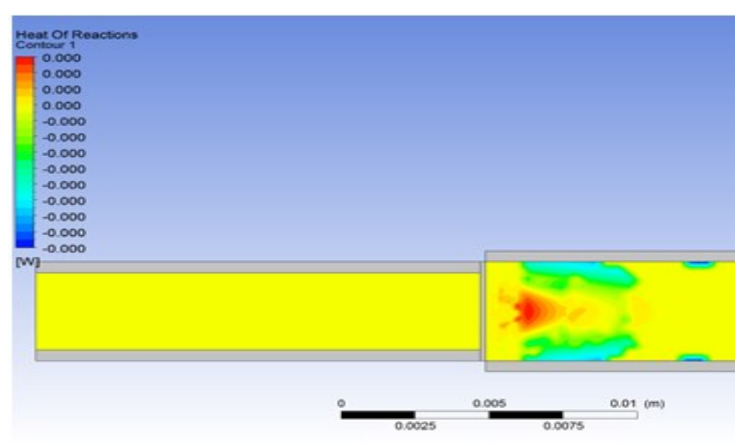

Fig. 6. Heat of reaction in quartz glass combustor at flow velocity $(U) 0.08 \mathrm{~m} / \mathrm{s}$ and $\varphi=1$.

Figure 6 presents the simulation results at flow velocity $(U) 0.08 \mathrm{~m} / \mathrm{s}$ on quartz glass combustor, wherein that condition heat of reaction value $=0$. This condition indicates that the flame on the combustor shows extinguishes condition. For the stainless steel combustor, when the flow velocity is increased $(U)=$ $0.082 \mathrm{~m} / \mathrm{s}$ the flame stabilizes begin to form and produces a temperature in the combustor of about $1740 \mathrm{~K}$. However, on quartz glass combustor at $(U)=0.082 \mathrm{~m} / \mathrm{s}$ the flame is still on extinguishes condition. Quartz glass combustor begins to show a stable flame on flow velocity $(U)=0.10 \mathrm{~m} / \mathrm{s}$ as shown in Fig. 5 . These results indicate that stainless steel combustor is capable of producing a stable flame at low-velocity flow.

\subsection{Flame stable area}

The stable flame area of the combustor type of rearward step with wire mesh occurs in the range of flow velocity between $0.82-0.6 \mathrm{~m} / \mathrm{s}$ for stainless steel combustor and $0.1-0.6 \mathrm{~m} / \mathrm{s}$ for quartz glass combustor. To find out more details about the phenomenon of stable flame in the combustor type of rearward step with wire mesh can be seen again Figure 5.

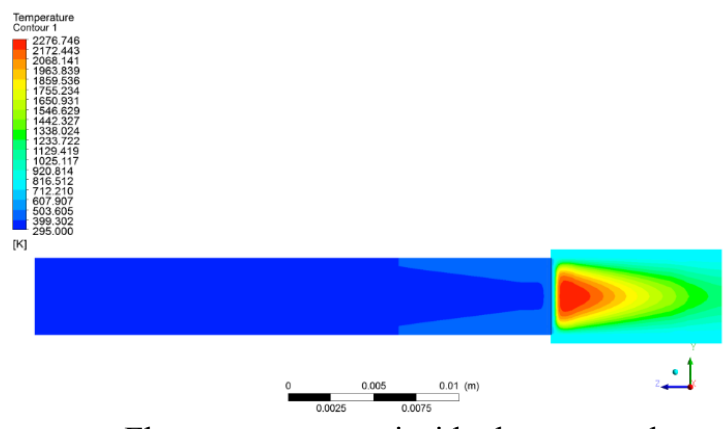

a. Flame temperature inside the quartz glass combustor, $U=0.6 \mathrm{~m} / \mathrm{s}$ and $\varphi=1$

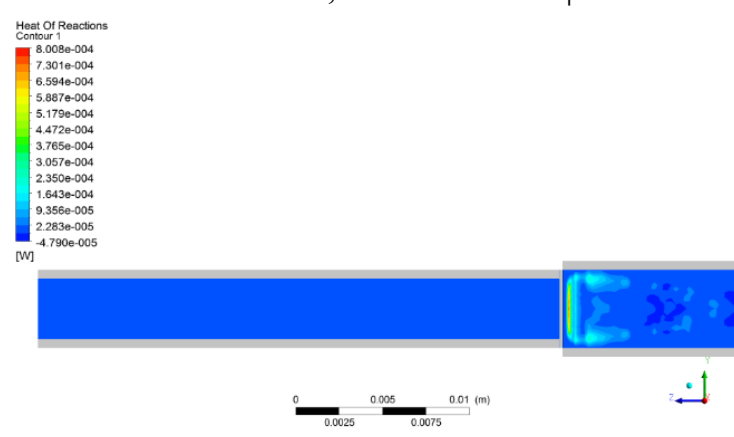

b. Heat of reaction in quartz glass combustor, $U=0.6$ $\mathrm{m} / \mathrm{s}$ and $\varphi=1$

Fig. 7. Flame stable condition near the blow off limit for quartz glass combustor.

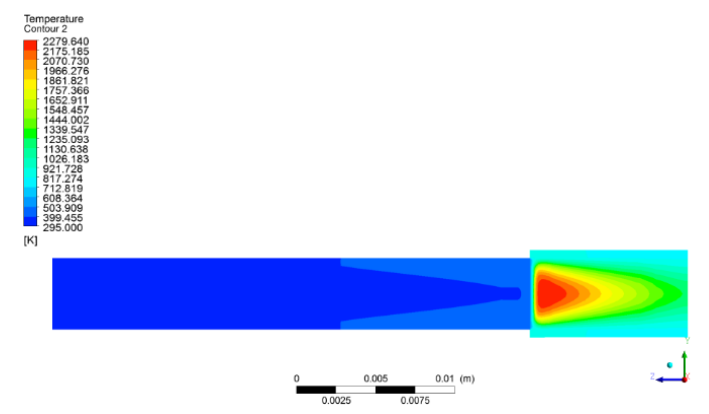

a.Flame temperature inside the stainless steel combustor, $U=0.6 \mathrm{~m} / \mathrm{s}$ and $\varphi=1$

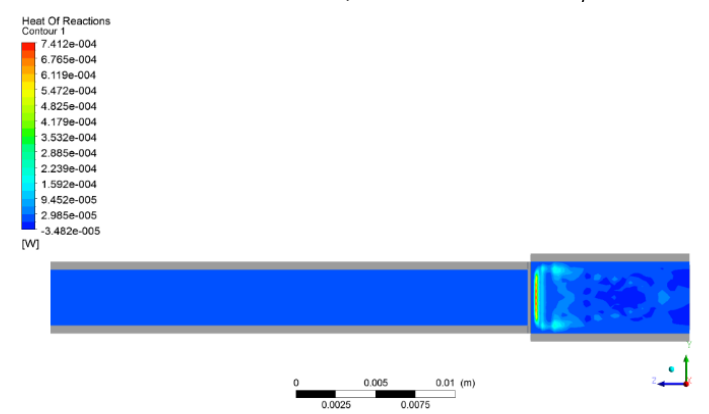

b. Heat of reaction in stainless steel combustor, $U=0.6 \mathrm{~m} / \mathrm{s}$ and $\varphi=1$

Fig. 8. Flame stable condition near the blow off limit for stainless steel combustor.

The results of observations in the area of stable flame can be seen that the temperature in the chamber in the combustor type of rearward step with wire mesh increases with increasing flow velocity. However, after 
reaching its peak point, the addition of flow velocity causes a decrease in temperature and also the flame position of the combustor. Flame shifted away from the wire when the flow velocity is increased. Figure 7 and 8 presented the flame stable in areas close to the blow-off limit $(\mathrm{U}=0.6 \mathrm{~m} / \mathrm{s})$ for quartz glass material combustor (Fig. 7) and stainless steel combustor (Fig.8). The Figures explains the symptoms of a decrease in temperature and the heat of reaction on quartz glass and stainless steel combustor. That condition is the area before the blow-off limit, but the flame is still in stable condition. Before the blow off, the flame on the combustor shows symptoms of decreased temperature and also decreased heat of reaction activity. Then, the flame will be extinguished along with the increase of flow velocity.

The comparison of the stable flame area between stainless steel combustor and glass combustor showed no significant difference. The difference only lies in the lower limit or low flow velocity, when the flow velocity increases both the combustor material have in common. In addition, the flame temperature in stainless steel combustor and glass combustor in the flow velocity range $0.1-0.6 \mathrm{~m} / \mathrm{s}$ shows similar tendencies.

\subsection{Blow off area}

Figure 9 presents the simulation results in flow velocity (U) $0.62 \mathrm{~m} / \mathrm{s}$. From Figure 9.a it is seen that the temperature inside the combustor type of rearward step with wire mesh is $354.44 \mathrm{~K}$ (for quartz combustor). This condition indicates that inflow velocity (U) $0.62 \mathrm{~m} / \mathrm{s}$ flame in micro combustion one blow off (blow off). This condition is also reinforced by heat of reaction analysis as shown in Figure 9b, where the heat of reaction in flow velocity (U) is $0.62 \mathrm{~m} / \mathrm{s}=0$.

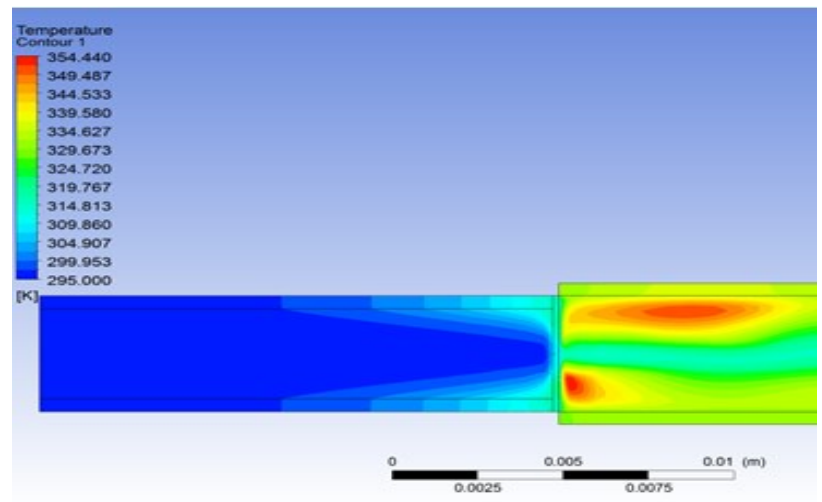

a.Flame temperature in quartz glass combustor, $U=0.62 \mathrm{~m} / \mathrm{s}$ and $\varphi=1$

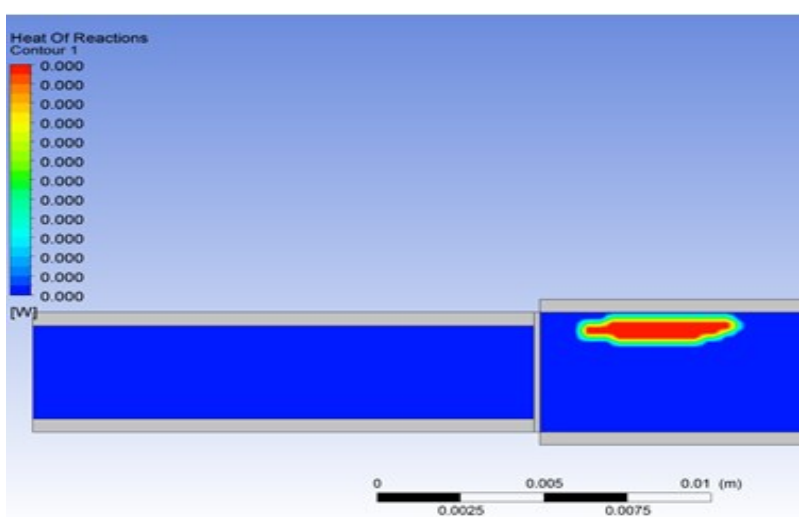

b. Heat of reaction in quartz glass combustor, $U=0.62$ $\mathrm{m} / \mathrm{s}$ and $\varphi=1$

Fig. 9. Flame condition of quartz glass combustor at blow off.

\section{Conclusion}

The focus of this study is to observe the combustor type of rearward step with wire mesh using the different material of combustor (stainless steel combustor and quartz glass combustor). Three dimension (3-D) numerical simulations of stainless steel combustor and quartz glass combustor has successfully demonstrated.

a. The stable flame area of the combustor type of rearward step with wire mesh and the equivalent ratio $\varphi=1$ occurs in flow velocity between 0.082 $0.6 \mathrm{~m} / \mathrm{s}$ (for stainless steel material) and $0.1-0.6$ $\mathrm{m} / \mathrm{s}$ (for quartz glass material).

b. The stainless steel combustor is capable of producing a stable flame at low-velocity flow.

c. Before the blow off, the flame on the combustor shows symptoms of decreased temperature and also decreased heat of reaction activity.

d. The comparison of the stable flame area between stainless steel combustor and glass combustor showed no significant difference.

This research was partly subsidized by Grant of International collaboration research PNPB Universitas Sebelas Maret 2018. The researchers gratefully acknowledge financial support from the LPPM Universitas Sebelas Maret, Surakarta, Indonesia.

\section{References}

1. D. C. Walther and J. Ahn, "Advances and challenges in the development of power-generation systems at small scales," Prog. Energy Combust. Sci., vol. 37, no. 5, pp. 583-610, (2011)

2. K. Maruta, "Micro and mesoscale combustion," Proc. Combust. Inst., vol. 33, no. 1, pp. 125-150, (2011)

3. S. K. Chou, W. M. Yang, K. J. Chua, J. Li, and K. L. Zhang, "Development of micro power generators - A review," Appl. Energy, vol. 88, no. 1, pp. 1-16, (2011)

4. A. C. Fernandez-Pello, "Micropower generation using combustion: Issues and approaches," Proc. Combust. Inst., vol. 29, no. 1, pp. 883-899, (2002)

5. L. C. Chia and B. Feng, "The development of a 
micropower (micro-thermophotovoltaic) device," $J$. Power Sources, vol. 165, no. 1, pp. 455-480, (2007)

6. M. Mikami, Y. Maeda, K. Matsui, T. Seo, and L. Yuliati, "Combustion of gaseous and liquid fuels in meso-scale tubes with wire mesh," Proc. Combust. Inst., vol. 34, no. 2, pp. 3387-3394, (2013)

7. B. Khandelwal, A. A. Deshpande, and S. Kumar, "Experimental studies on flame stabilization in a three step rearward facing configuration based micro channel combustor," Appl. Therm. Eng., vol. 58, no. 1-2, pp. 363-368, (2013)

8. H. Saputro et al., "The CFD Simulation of Cyclone Separator without and with the Counter-cone in the Gasification Process," IOP Conf. Ser. Mater. Sci. Eng., (2018)

9. D. G. Norton and D. G. Vlachos, "A CFD study of propane/air microflame stability," Combust. Flame, vol. 138, no. 1-2, pp. 97-107, (2004)

10. F. A. Munir and M. Mikami, "A numerical study of propane-air combustion in meso-scale tube combustors with concentric rings," J. Therm. Sci. Technol., vol. 10, no. 1, p. JTST0008-JTST0008, (2015)

11. M. Z. Hassan and F. A. Munir, "A numerical study of flame stabilization in single channel and counterflow meso scale combustor," Int. J. Mech. Mechatronics Eng., vol. 16, no. 4, pp. 1-8, (2016) 